\title{
Effect of Gamma Irradiatoin on Chlorophyll Metabolism in Dolichos, Vigna and Phaseolus species
}

\author{
S. S. N. Sinha ${ }^{2}$ and R. S. Himanshu ${ }^{3}$
}

Received December 27, 1982

Different plants, with special reference to their chlorophyll metabolism, have been studied by different workers such as Arnon (1949), Aruga and Monsi (1963), Anderson and Boardman (1964), Wood and Bachelor (1969), Gopal Rao (1973) Katyayani et al. (1978).

Dolichos, Vigna and Phaseolus, the members of family Papilionaceae, are mainly grown for their beans which are used as vegetables and pulses. It is well known to the biologists that some bacteria, in symbiotic association with leguminous plants, fix atmospheric nitrogen which leads to the formation of amino acids and proteins. These products are translocated to the seeds during the period of their formation. Due to this, the seeds of the leguminous plants contain higher amount of protein in comparison to the seeds of other plants.

The mechanism involved in the nitrogen fixation indicates that its efficiency is regulated by the supply of the host photosynthate.

Therefore, induction of higher amount of chlorophyll may affect the photosynthetic activity of the plant, which in turn, may affect the yield of the plant concerned.

Keeping this fact in mind, the present piece of work has been carried out to see the effect of acute gamma radiation on the chlorophyll metabolism of the plants concerned, and their yield at corresponding doses.

\section{Materials and methods}

Pure line seeds of Dolichos, Vigna and Phaseolus were exposed to $1.25 \mathrm{KR}, 2.5$ $\mathrm{KR}, 5.0 \mathrm{KR}, 10.0 \mathrm{KR}$ and 15.0 KR doses of gamma irradiation from $\mathrm{Co}^{60}$ source. Plants were grown from these seeds and control plants were maintained in each case. Chlorophyll $a$, chlorophyll $b$ and total chlorophyll content was estimated in the leaf of all the samples and the effect of gamma rays on chlorophyll metabolism was measured in terms of $\mathrm{mg} / \mathrm{gm}$ fresh weight of leaf.

Chlorophyll content in terms of $\mathrm{mg} / \mathrm{gm}$ fresh weight of leaf was calculated by the method suggested by Arnon (1949), Anderson and Boardman (1964) and Wood and Bachelord (1969). Care was taken in selecting leaf materials of the same age (4 weeks after sowing) randomly from different plants.

\footnotetext{
1 Part of Ph. D. thesis by the second author.

2 Planning Officer, Rajendra Agricultural University, Pusa, Bihar, India.

3 Reader, Department of Botany, Jamshedpur Co-operative College, Jamshedpur, India.
} 


\section{Observations and results}

Chlorophyll $b$ was recorded to be more in amount than chlorophyll $a$ in all the cases investigated.

In Dolichos lablab Linn., total chlorophyll content decreased at lower doses upto $5 \mathrm{KR}$ but increased at $10 \mathrm{KR}$ and $15 \mathrm{KR}$ when compared to chlorophyll content of control plants. The maximum amount $(0.585 \mathrm{mg} / \mathrm{gm})$ was noted at $15 \mathrm{KR}$ dose. The total chlorophyll content in control plants was recorded to be $0.497 \mathrm{mg} / \mathrm{gm}$ (Table 1, Graph 1). Here, the weight of 100 seeds went on increasing with the incresae in the radiation dose.

But Dolichos biflorus Linn. proved to be more radiosensitive than the former where an increase in total chlorophyll content was noted at all dose levels. The control value $(0.667 \mathrm{mg} / \mathrm{gm})$ was the minimum and the maximum value $(0.937$ $\mathrm{mg} / \mathrm{gm})$ was recorded at $1.25 \mathrm{KR}$ dose. The minimum value among treated plants $(0.734 \mathrm{mg} / \mathrm{gm})$ was recorded at $10 \mathrm{KR}$ dose level (Table 1, Graph 2). However, a linearity existed as regards the radiation dose and the weight of 100 seeds.

Table 1. Effect of gamma irradiation on chlorophyll content of leaf in two species of Dolichos in $\mathrm{M}_{1}$ generation

\begin{tabular}{cccccc}
\hline \hline Plant name & $\begin{array}{c}\text { Dose in } \\
\text { KR }\end{array}$ & $\begin{array}{c}\text { Chl. a } \\
\mathrm{mg} / \mathrm{gm}\end{array}$ & $\begin{array}{c}\text { Chl. b } \\
\mathrm{mg} / \mathrm{gm}\end{array}$ & $\begin{array}{c}\text { Total chl. } \\
\mathrm{mg} / \mathrm{gm}\end{array}$ & $\begin{array}{c}\text { Weight of } \\
\text { 100 seeds } \\
\text { in grams }\end{array}$ \\
\hline $\begin{array}{c}\text { Dolichos lablab } \\
\text { var. 3/76 }\end{array}$ & 0 & 0.175 & 0.322 & 0.497 & 10.642 \\
& 1.25 & 0.176 & 0.319 & 0.495 & 11.675 \\
& 2.5 & 0.155 & 0.277 & 0.432 & 11.692 \\
& 5.0 & 0.151 & 0.296 & 0.447 & 12.698 \\
& 10.0 & 0.197 & 0.372 & 0.569 & 14.714 \\
& 15.0 & 0.204 & 0.381 & 0.585 & 14.721 \\
\hline Dolichos biflorus & 0 & 0.241 & 0.426 & 0.667 & 2.947 \\
var. local & 1.25 & 0.325 & 0.612 & 0.937 & 3.268 \\
& 2.5 & 0.278 & 0.497 & 0.775 & 3.387 \\
& 5.0 & 0.291 & 0.494 & 0.785 & 3.494 \\
& 10.0 & 0.249 & 0.485 & 0.734 & 3.612 \\
& 15.0 & 0.298 & 0.494 & 0.792 & 3.719 \\
\hline
\end{tabular}

Out of the three varieites of Vigna unguiculata (L.) Walp subspecies cylindrica, the variety Rituraj showed a negative trend in chlorophyll metabolism. The control value $(0.567 \mathrm{mg} / \mathrm{gm})$ was the maximum value. The minimum value $(0.378$ $\mathrm{mg} / \mathrm{gm}$ ) was noted at $1.25 \mathrm{KR}$ dose and the maximum value among the irradiated population $(0.541 \mathrm{mg} / \mathrm{gm})$ was recorded at $10 \mathrm{KR}$ dose level. In this variety, radiation seemed to retard the chlorophyll metabolism. The decrease in value of total chlorophyll was more at lower dose levels than at the higher ones (Table 2, Graph 5).

A somewhat similar trend was recorded in the variety Pusa Dofasli of the same species. All the lower doses decreased the amount of chlorophyll as compared to that in control plants $(0.546 \mathrm{mg} / \mathrm{gm})$ but there was an increase in chlorophyll content at $15 \mathrm{KR}$ dose where it was noted as $0.596 \mathrm{mg} / \mathrm{gm}$. The minimum value $(0.493$ 
$\mathrm{mg} / \mathrm{gm}$ ) was recorded at $2.5 \mathrm{KR}$ dose levlel (Table 2, Graph 3).

In the variety Pusa Falguni of the same species, a decrease in chlorophyll content was recorded at lower doses ( $1.25 \mathrm{KR}$ and $5 \mathrm{KR})$ but an increase was noted at
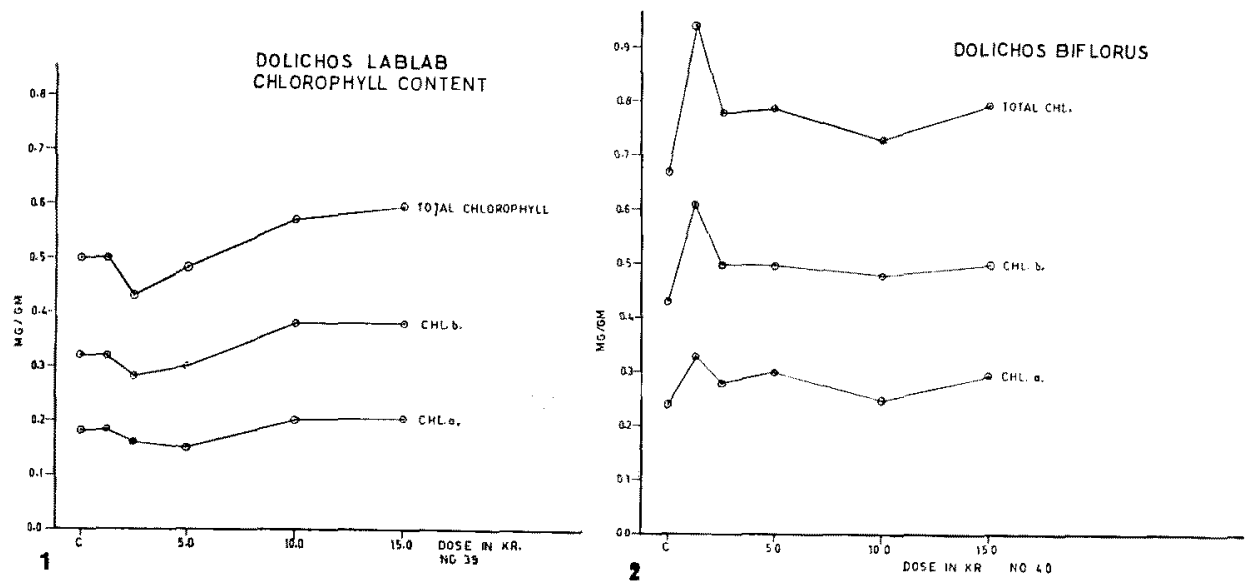

Graphs 1-2. 1, effect of gamma irradiation on chlorophyll metabolism in leaves of Dolichos lablab L. 2, effect of gamma irradiation on chlorophyll metabolism in leaves of Dolichos biflorus $\mathrm{L}$.

Table 2. Effect of gamma irradiation on chlorophyll content of leaf in three varieites of Vigna unguiculata (L.) Walf subspecies

cylindrica in $\mathrm{M}_{1}$ generation

\begin{tabular}{lccccc}
\hline Name of variety & $\begin{array}{c}\text { Dose in } \\
\text { KR }\end{array}$ & $\begin{array}{c}\text { Chl. a } \\
\mathrm{mg} / \mathrm{gm}\end{array}$ & $\begin{array}{c}\text { Chl. b } \\
\mathrm{mg} / \mathrm{gm}\end{array}$ & $\begin{array}{c}\text { Total chl. } \\
\mathrm{mg} / \mathrm{gm}\end{array}$ & $\begin{array}{c}\text { Weight of } \\
\text { 100 seeds } \\
\text { in grams }\end{array}$ \\
\hline Pusa Dofasli & 0 & 0.194 & 0.352 & 0.546 & 7.6 \\
& 1.25 & 0.172 & 0.328 & 0.500 & 6.3 \\
& 2.5 & 0.163 & 0.330 & 0.493 & 7.1 \\
& 5.0 & 0.181 & 0.326 & 0.507 & 7.9 \\
& 10.0 & 0.160 & 0.288 & 0.448 & 7.9 \\
& 15.0 & 0.214 & 0.382 & 0.596 & 14.7 \\
\hline Pusa Falguni & 0 & 0.203 & 0.390 & 0.593 & 6.4 \\
& 1.25 & 0.185 & 0.327 & 0.512 & 6.6 \\
& 2.5 & 0.220 & 0.411 & 0.631 & 6.7 \\
& 5.0 & 0.167 & 0.304 & 0.471 & 6.7 \\
& 10.0 & 0.230 & 0.414 & 0.644 & 5.7 \\
& 15.0 & 0.258 & 0.461 & 0.719 & 5.6 \\
\hline Rituraj & 0 & 0.195 & 0.372 & 0.567 & 7.4 \\
& 1.25 & 0.135 & 0.243 & 0.378 & 7.8 \\
& 2.5 & 0.167 & 0.318 & 0.485 & 8.2 \\
& 5.0 & 0.193 & 0.346 & 0.539 & 8.1 \\
& 10.0 & 0.198 & 0.343 & 0.541 & 6.0 \\
& 15.0 & 0.173 & 0.319 & 0.492 & 5.8 \\
\hline
\end{tabular}

$2.5 \mathrm{KR}, 10 \mathrm{KR}$ and $15 \mathrm{KR}$ dose levels. The maximum value $(0.719 \mathrm{mg} / \mathrm{gm})$ was recorded at $15 \mathrm{KR}$ dose and the minimum $(0.471 \mathrm{mg} / \mathrm{gm})$ at $5 \mathrm{KR}$ dose as compared with control value of $0.593 \mathrm{mg} / \mathrm{gm}$ (Table 2, Graph 4). All the three varieites 
of $V$. unguiculata responded differently to the radiation dose, as regards the weight of the equal number of seeds. In the variety Pusa Dofasli, the lower doses seemed to be inhibitory while at higher doses, the seed weight incresed.
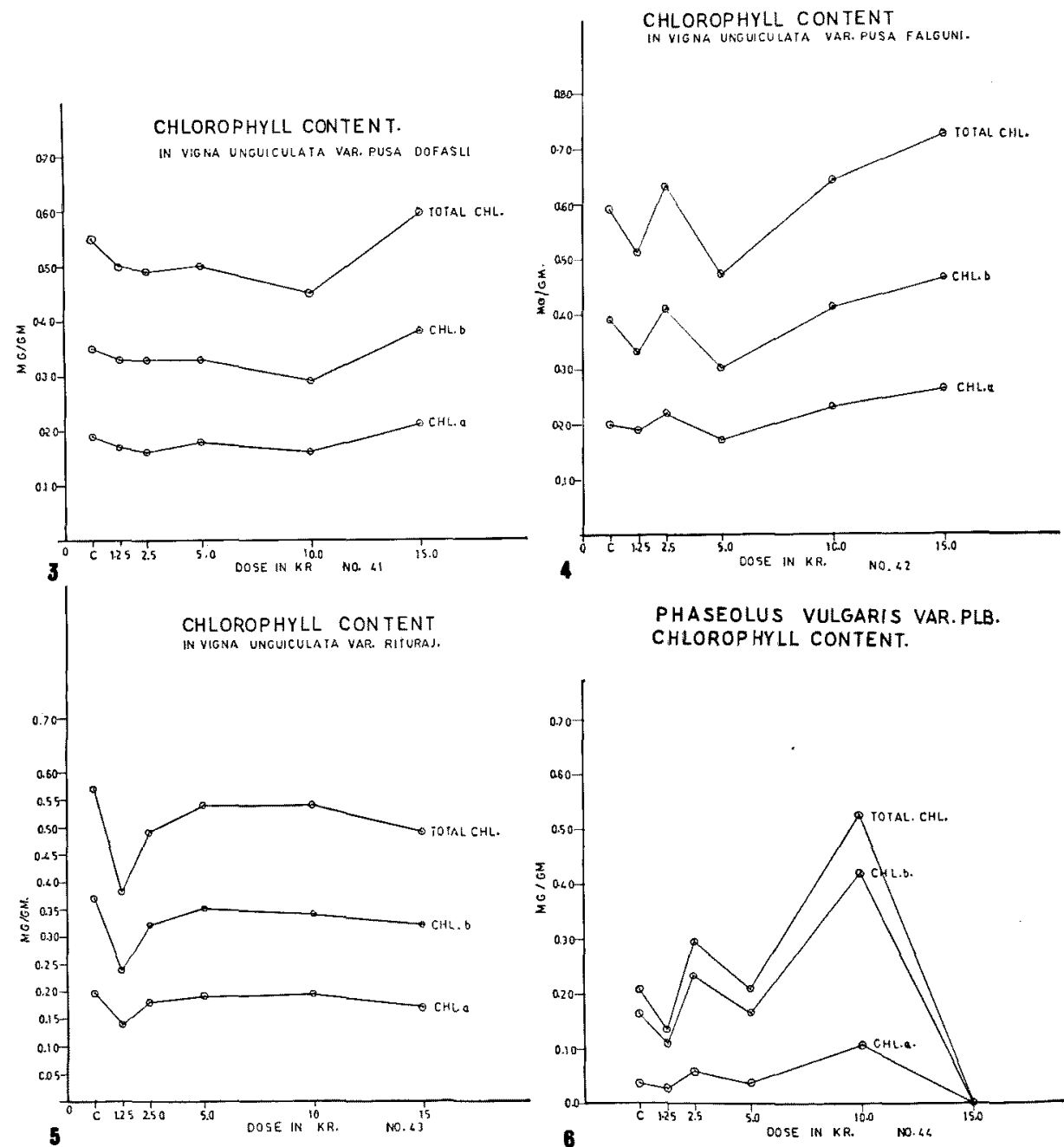

4

PHASEOLUS VULGARIS VAR. PLB.

CHLOROPHYLL CONTENT.

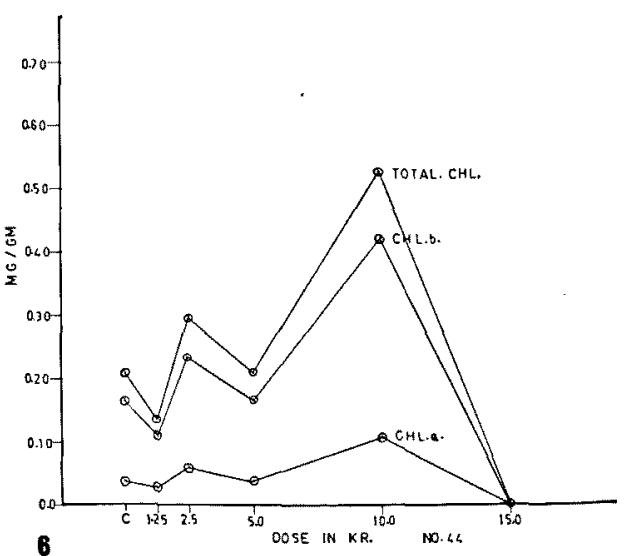

Graphs 3-6. 3, effect of gamma irradiation on chlorophyll metabolism in leaves of Vigna unguiculata (L) Walp subspecies cylindrica var. Pusa Dofasli. 4, effect of gamma irradiation on chlorophyll metabolism in leaves of Vigna unguiculata (L) Walp subspecies cylindrica var. Pusa Falguni. 5, effect of gamma irradiation on chlorophyll metabolism in leaves of Vigna unguiculata (L) Walp subspecies cylindrica var. Rituraj. 6, effect of gamma irradiation on chlorophyll metabolism in leaves of Phaseolus vulagris L. var. PLB.

In Pusa Falguni, the higher doses (10 KR and $15 \mathrm{KR}$ ) registered inhibitory effect while the lower doses induced some positive results. In the variety $R$. R., higher values of seed weight was observed at $1.25 \mathrm{KR}$ and $5 \mathrm{KR}$. But higher and lower values of this dose proved to be inhibitory. 
Table 3. Effect of gamma irradiation on chlorphyll content of leaf in four variettes belonging to two species of Phaseolus in $\mathrm{M}_{1}$ generation

\begin{tabular}{lccccc}
\hline $\begin{array}{c}\text { Name of species } \\
\text { and variety }\end{array}$ & $\begin{array}{c}\text { Dose in } \\
\text { KR }\end{array}$ & $\begin{array}{c}\text { Chl. a } \\
\mathrm{mg} / \mathrm{gm}\end{array}$ & $\begin{array}{c}\text { Chl. b } \\
\mathrm{mg} / \mathrm{gm}\end{array}$ & $\begin{array}{c}\text { Total chl. } \\
\mathrm{mg} / \mathrm{gm}\end{array}$ & $\begin{array}{c}\text { Weight of } \\
\text { 100 seeds } \\
\text { in gram }\end{array}$ \\
\hline Phasolus vulgaris $\mathrm{L}$. & 0 & 0.043 & 0.165 & 0.208 & 26.6 \\
variety PLB & 1.25 & 0.028 & 0.109 & 0.137 & 33.4 \\
& 2.5 & 0.060 & 0.237 & 0.297 & 33.4 \\
& 5.0 & 0.043 & 0.164 & 0.207 & 33.1 \\
& 10.0 & 0.107 & 0.419 & 0.526 & 27.5 \\
\hline P. vulgaris $\mathrm{L}$ variety EC. & 0 & 0.050 & 0.190 & 0.240 & 34.6 \\
& 1.25 & 0.044 & 0.179 & 0.223 & 35.3 \\
& 2.5 & 0.062 & 0.261 & 0.323 & 37.3 \\
& 5.0 & 0.051 & 0.197 & 0.248 & 37.3 \\
& 10.0 & 0.085 & 0.336 & 0.421 & 37.3 \\
\hline v. lunatus $\mathrm{L}$. & 0 & 0.165 & 0.319 & 0.484 & 29.0 \\
& 1.25 & 0.292 & 0.561 & 0.853 & 31.5 \\
& 2.5 & 0.189 & 0.402 & 0.591 & 28.7 \\
& 5.0 & 0.201 & 0.371 & 0.572 & 15.5 \\
& 10.0 & 0.163 & 0.322 & 0.485 & 41.0 \\
\hline P. lunatus $\mathrm{L}$ P. & 0 & 0.183 & 0.365 & 0.548 & 24.4 \\
variety EC & 1.25 & 0.179 & 0.339 & 0.518 & 25.5 \\
& 2.5 & 0.169 & 0.332 & 0.501 & 28.7 \\
& 5.0 & 0.130 & 0.254 & 0.384 & 23.6 \\
& 10.0 & 0.108 & 0.238 & 0.346 & 25.8 \\
& 15.0 & 0.085 & 0.219 & 0.304 & 28.9 \\
\hline
\end{tabular}

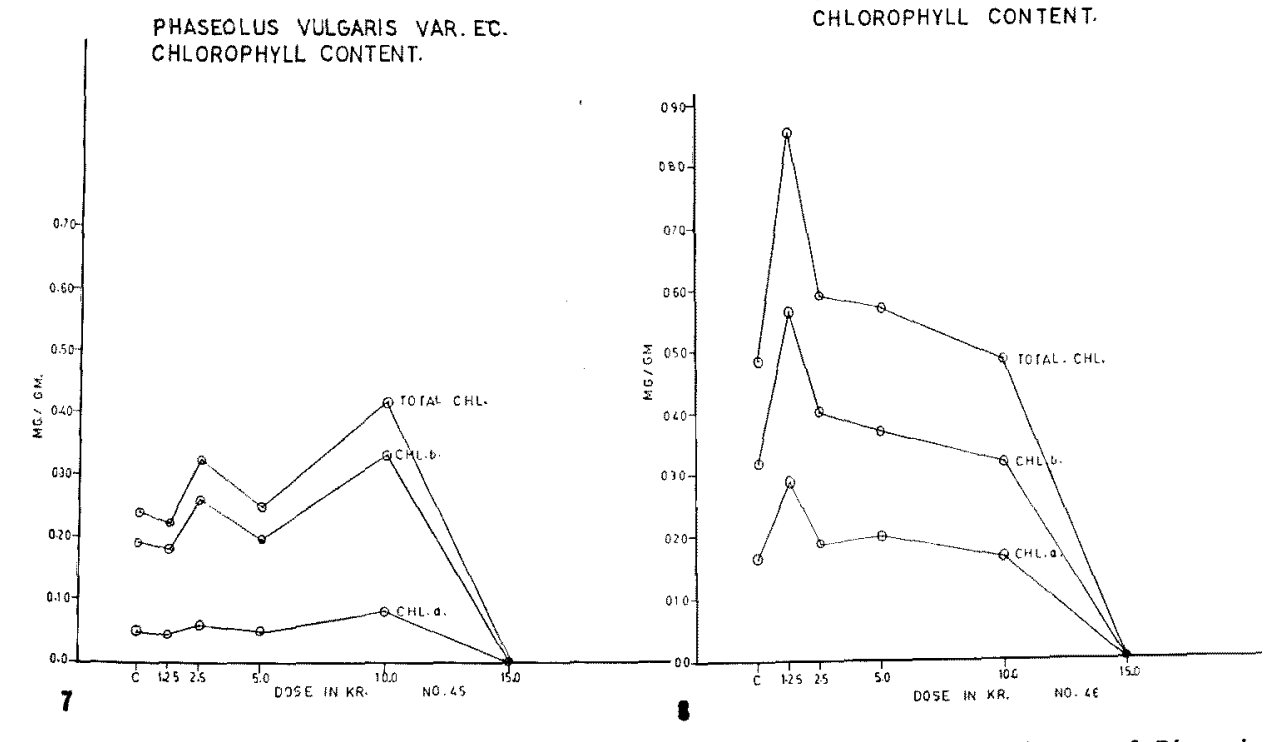

Graphs 7-8. 7, effect of gamma irradiation on chlorophyll metabolism in leaves of Phaseolus vulgaris L. var. EC. 8, effect of gamma irradiation on chlorophyll metabolism in leaves of Phaseolus lunatus L. var. PI. 
In Phaseolus vulgaris Linn., both the varieties PLB and EC exhibited a decrease at lower dose levels and increase at higher dose levels as compared to the control value.

In variety PLB, total chlorophyll in control plants was recorded as 0.208 $\mathrm{mg} / \mathrm{gm}$. The mxaimum value $(0.526 \mathrm{mg} / \mathrm{gm})$ was noted at $10 \mathrm{KR}$ dose and the minimum $(0.137 \mathrm{mg} / \mathrm{gm})$ was recorded at $1.25 \mathrm{KR}$ dose. The plants at $2.5 \mathrm{KR}$ dose level exhibited an increse $(0.297 \mathrm{mg} / \mathrm{gm})$ while those at $5 \mathrm{KR}$ dose level recorded a slight decreae $(0.207 \mathrm{mg} / \mathrm{gm})$ (Table 3 , Graph 6$)$.

In variety $E C$ of the same species,

PHA SEOLUS LUNATUS VAR. EC. CHLOROPHYLL CONTENT

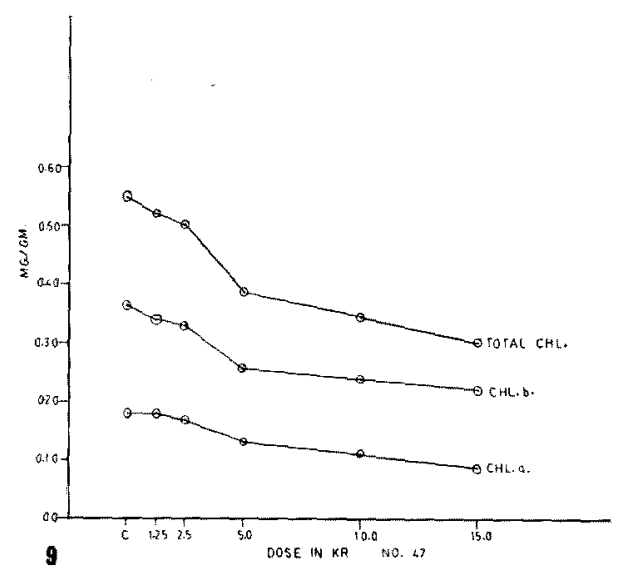

Graph. 9. Effect of gamma irradiation on chlorophyll metabolism in leaves of Phaseolus lunatus L. var. EC. the minimum value $(0.223 \mathrm{mg} / \mathrm{gm})$ was recorded at $1.25 \mathrm{KR}$ dose as compared to control value of $0.240 \mathrm{mg} / \mathrm{gm}$. All other treatments showed incresae in chlorophyll content, the maximum $(0.421 \mathrm{mg} / \mathrm{gm})$ being recorded at 10 $\mathrm{KR}$ dose level. The variety EC seemed to be more radiosensitive than variety PLB. In both the varieties, a tendency of decrease in mutagenic effect was observed at $5 \mathrm{KR}$ dose level after a significant increase at $2.5 \mathrm{KR}$ dose. The dose $1.25 \mathrm{KR}$ seemed to be detrimental to chlorophyll metabolism while $10 \mathrm{KR}$ dose appeared to be the greatest stimulant in this respect (Table 3, Graph 7).

In $P$. lunatus Linn., the variety PI seemed to be positively radiosensitive and the variety EC negatively so. In the former, an incresse in chlorophyll content over the control value of $0.484 \mathrm{mg} / \mathrm{gm}$ was noted at all dose levels. The maximum value $(0.853 \mathrm{mg} / \mathrm{gm})$ was observed at $1.25 \mathrm{KR}$ dose and the minimum $(0.485 \mathrm{mg} / \mathrm{gm})$ at $10 \mathrm{KR}$ dose level. The positive trend towards increase in chlorophyll content gradually declined from $1.25 \mathrm{KR}$ to $10 \mathrm{KR}$ dose level (Table 3, Graph 8).

In contrast, there seemed to be a gradual and uniform decrease in chlorophyll content in irradiated population as compared to the control value of $0.548 \mathrm{mg} / \mathrm{gm}$ in the variety $\mathrm{EC}$ of the same species. The minimum value $(0.304 \mathrm{mg} / \mathrm{gm})$ was recorded at $15 \mathrm{KR}$ dose. The lower doses proved less detrimental than higher doses to chlorophyll metabolism (Table 3, Graph 9).

In $P$. vulgaris, the seed weight in all the treated populations increases in comparison to the control plant. But at $10 \mathrm{KR}$ dose the seed weight decreased, which was, however, higher than that of the control plants.

In $P$. vulgaris var. EC, the seed weight increased upto $2.5 \mathrm{KR}$ dose, the value remained constant even at $10 \mathrm{KR}$ dose. In both the varieties of $P$. lunatus (viz. PI and EC), the seed weight did not show any correlation with the radiation dose 
(Table 3).

\section{Discussion}

The effect of gamma rays on chlorophyll metabolism was measured in terms of chlorophyll content $\mathrm{mg} / \mathrm{gm}$ fresh weight of leaf. The data presented in Tables 1 to 3 and Graphs 1-9 showed that $10 \mathrm{KR}$ and $15 \mathrm{KR}$ doses caused an increase in the content of chlorophyll a, chlorophyll b and total cholrophyll in Dolichos lablab as compared to that in control leaf. It caused a decrease in chlorophyll content at 1.25 $\mathrm{KR}, 2.5 \mathrm{KR}$ and $5 \mathrm{KR}$ doses. The maximum increase and decrease were noted at $15 \mathrm{KR}$ dose and $2.5 \mathrm{KR}$ dose respectively (Table 1 ).

In $D$. biflorus, the gamma rays caused as increase in chlorophyll content at all the dose levels over that of control, the maximum increase being observed at 1.25 KR dose (Table 1).

In Vigna unguiculata variety Pusa Dofasli, the radiation caused an increase at $15 \mathrm{KR}$ dose and decrease at all other doses.

The variety Pusa Falguni of the same species recorded an increase at $2.5 \mathrm{KR}, 10$ $\mathrm{KR}$ and $15 \mathrm{KR}$ dose levels, the maximum increase being recorded at $15 \mathrm{KR}$ dose.

But the variety Rituraj of Vigna recorded only decrease in chlorophyll content at all dose levels as compared to that of control (Table 2).

The variety PLB of Phaseolus vulgaris, recorded incresae in chlorophyll content at $2.5 \mathrm{KR}$ and $10 \mathrm{KR}$ dose levels whereas the var. EC of the same species exhibited an increase at $2.5 \mathrm{KR}, 5 \mathrm{KR}$ and $10 \mathrm{KR}$ dose levels. The maximum increase in both the varieties was noted at $10 \mathrm{KR}$ dose level (Table 3).

The variety PI of $P$. lunatus recorded an increase in chlorophyll content over that of control at all dose levels, the maximum increase being noted at $1.25 \mathrm{KR}$ dose level. In contrast to this, gamma rays appeared to have inhibited the rate of chlorophyll metabolism in the variety EC of the same species at all dose levels as compared to that in control plants (Table 3).

The $10 \mathrm{KR}$ and $15 \mathrm{KR}$ doses seemed to cause greatest stimulation to chlorophyll metabolism in five out of nine types, while $1.25 \mathrm{KR}$ dose produced the greateast stimulation in two of them. In the remaining two types, radiation caused decrease in chlorophyll content at all dose levels.

Similar observations were made by Katyayani et al. (1978) in Phaseolus aureus, Gopal Rao (1973) in the same species when treated with riboflavin, and Rao and Rao (unpublished) in Okra with gamma rays. They had reported increase in chlorophyll metabolism at higher doses of gamma rays ( 8 to $10 \mathrm{KR}$ ) and decrease in the content at lower doses ( 5 to $6 \mathrm{KR})$.

An increase in chlorophyll content at $1.25 \mathrm{KR}$ dose in $P$. lunatus variety $\mathrm{PI}$ and in Dolichos biflorus in contrast to other five varieties and species in which lower doses decreased the content can be explained on the basis that the cytological and genetic make up of these two types was different and hence it had differential response to different doses of irradiation.

In the variety Pusa Dofasli of Vigna unguiculata, 100 seeds weight was almost double at $15 \mathrm{KR}$ dose level as compared to other doses. This might be attributed 
to the fact that radiation caused greater sterility at this highest dose level, so less number of seeds were formed per pod, which led to the increase in size of the seeds. Thereby the 100 seeds weight might have shown an apparent increase as compared to the control.

In the variety PI of Phaseolus lunatus, 100 seeds weight was almost half at $5 \mathrm{KR}$ dose than that at other doses. This might be due to the fact that the number of seeds per plant as well as the number of pods per plant were the greatest at this dose, so the seeds formed were smaller in size. Thus the 100 seeds weight might have shown an appreciable apparent decrease over those of control plants and treated plants at other doses.

The dose $15 \mathrm{KR}$ appeared to be most damaging for PLB and EC varieties of Phaseolus vulgaris and the variety PI of Phaseolus lunatus whereas no such phenomenon was noted in other species and varieties. The plants did not survive at this dose level beyond the 20th day. This might be due to the fact that the above noted three varieties were more susceptible to the damages caused by radiation than other varieties and species under investigation. The death might have occurred due to agromomic reasons also. This was applicable to control plants as well.

Although a clear picture does not exist in all the treated plants as regards their response to the radiation dose, in terms of the seed weight and their correlation with chlorophyll content, it is quite apparent that the chlorophyll content has got a role to play in determining the weight of the seeds. In Dolichos lablab and D. biflorus the chlorophyll content and seed weight registered a linear relationship. But the species and varieties of Vigna and Phaseolus did not show such trend. This may be due to their different radiosensitive nature. However, it needs further investigation.

\section{Abstract}

The effect of gamma irradiation on chlorophyll metabolism was studied in leaves of Dolichos, Vigna and Phaseolus species. The dry seeds were exposed to 1.25 KR, 2.5 KR, 5.0 KR, 10.0 KR and 15.0 KR doses of gamma irradiation and leaves from plants recovered from them as well as from control plants were tested for Chl. a, Chl. b and total chlorophyll contents. A comparison was made between chlorophyll contents of leaves from irradiated and non-irradiated populations. Chlorophyll content decreased at lower doses and incerased at higher doses in Dolichos lablab L., Vigna unguiculata L. and Phaseolus vulgaris L. But in D. biflorus and $P$. lunatus L. var. PI irradiation increased the chlorophyll content at all dose levels. In contrast the variety EC of $P$. lunatus $L$. recorded a decrease in chlorophyll content at all dose levels. The amount of chlorophyll $b$ was more than that of chlorophyll a in all the plants investigated.

\section{References}

Anderson and Boardman, 1964. In C.P. Malik's Estimation of Chlorophyll Content Plant Physiology Vikas Publications, Delhi.

Arnon, D. I. 1949. Copper enzymes in isolated chloroplasts, polyphenol oxidase in Beta vulgaris. Plant Physiol. 24: 1-15. 
Aruga, Y. and Monsi, M. 1963. Cholorophyll amounts as an indicator of matter production in bio-communities. Plant and Cell Physiol. 4: 29-39.

Gopal Rao, P. 1973. Influence of riboflavin on growth, respiration and chlorophyll content and protein content in green gram (Phaseolus radiatus Linn). Curr. Sci. 42: 580-581.

Katyayani, M., Rao, D., Rao, S. N. and Krishnamurty, P. 1978. Gamma irradiation induced physiological variabilities in Phaseolus aureus Roxb. J.I.B.S. 57 (Suppl.): 91 (abstract).

- and Rao, D. 1980. Variability and radio-sensitivity of Vigna radiata (L.) Wilcez. var. Baisakhi as affected by gamma rays. J.I.B.S. 59 (Suppl): 116 (abstract).

Kachroo, P. 1970. Pulse Crops of India I.C.A.R., New Delhi.

Wood, J. P. and Bachelord, E. P. 1969. Variations in chlorophyll concentration in the foliage of radiata pine. Forestry: 33: 9-14. 